\title{
Residency training in the United States: What foreign medical graduates should know
}

\author{
Samuel A. Adebonojo ${ }^{*}$, Oluwatope A. Mabogunje ${ }^{* *}$ and A. Thomas Pezrella ${ }^{\dagger}$ \\ * Surgical Service, Veteran Affairs Medical Center, Dayton, Ohio, \\ Professor of Surgery, Wright State University School of Medicine Associate Director, \\ General Surgery Residency Training Program Dayton, Ohio 45428 \\ ** Surgical Service, Veteran Affairs Medical Center, Dayton, Ohio, \\ Professor of Surgery, Wright State University School of Medicine Dayton, Ohio 45428
}

${ }^{\dagger}$ Good Samaritan Hospital, Mt. Vernon, Illinois, USA 62864

\begin{abstract}
Summary
This communication provides useful information for Foreign Medical Graduates (FMGs) planning to pursue post-graduate residency training in the United States of America (USA). While the number of residency training positions is shrinking, and the number of United States graduates has steadily declined over the past decade, the number of FMGs has also steadily increased. Unfortunately, as a result of the terrorist attack of September 11, 2001, the problem of obtaining training visas and sponsorship by the Educational Commission for Foreign Medical Graduates (ECFMG) will remain major problems for FMGs. This present review is by no means exhaustive. It should serve as a guideline to more detailed and focused information. It is extremely important to network with friends, family, and professional colleagues regarding the subjective and objective aspects of pursuing graduate medical education (GME) in the USA. Though the process is very protracted and at times frustrating and depressing; the visa hurdle will be the ultimate barrier to overcome. However, majority of FMGs eventually achieve the ultimate goal of obtaining superb training and experience in the United States. We highly recommend the book by Kenneth V. Iserson entitled "Iserson's Getting Into A Residency: A Guide for Medical Students" published by Galen Press Limited, Tucson, Arizona (ref \# 10). It is a very useful source of information for medical students and residents planning further residency training in the United States of America. Useful Internet addresses are listed in Appendix 1 .
\end{abstract}

Keywords: Foreign medical graduates, International medical graduates, Residency training programmes in USA, ECFMG.

\section{Résumé}

Cette communication donnes des informations formidables pour les diplômes Médicaux Etrangers (DME) qui projettent de poursuivre la formation d'internat du troisième cycle aux Etat Unis d'Amérique (USA). Tandis que le nombre des diplômés des Etats Unis étaient en baisse au cours des dernieres décennies, le nombre des DME a également régulierement élevé.

Malheureusement, à la suite d'attentat terroriste du 11 septembre, 2001, le problème d'obtenir le visa de formation et parrainage de la part de la Commission d'Education pour des Diplômais Médicaux Etangers (CEDME) deviendra un problème important pour DME. Cette étude n'est pas traité à fond. Elle devrait tenir lieu d'une règle générale des informations beaucoup plus détaillée et l'objet de profondes iniquétude. C'est extrêmement important d'établir un réseau de contacts avec des amis, la famille, et organisme professionnel en ce qui concerne les aspects subjectifs et objectifs de suivre le Diplôme d'Education Médicale (DEM) aux USA. Quoique le processus soit très prolongé et parfois frustrant et déprimant, franchir l'obstacle du visa sera une barriere à surmonter. Toutefois, la plus grande partie des DME en fin de compte arriveront à obtenir la formation et l'experience aux Etats Unis. Nous recommandons fortement un livre par Kenneth V. Iserson intitulé: "Iserson's getting into a residency" il constitute un guide pour les Etudiants en Médecine; publié par Galen Press Limited, Tueson, Arizone (ref.\# 10) C'est un livre qui donne des renseignements nécessaires pour les étudiants en médecine et les internes qui projettent de suivre des formations supérieures sur l'internat aux Etats Unis. Quelque adresses très utiles sur l'Internet fiqurent dans le premier appendice.

Introduction

An important goal of training for foreign medical graduates (FMGs) in the USA is to provide quality graduate medical education for qualified FMGs who would return to their home countries on the completion of training. Such returnee-physicians would have a multiplier effect in expanding health care initiatives and providing local training programmes in their homelands. However, qualified FMGs may be motivated to seek further training in the US for rather complex reasons, including a desire to improve on inadequate training at home, or to seek advanced training in order to upgrade the medical services at home, or simply to emigrate for personal or professional reasons.

In a review of the World Directory of Medical Schools published by the World Health Organization (WHO) from 1995 - 1996, there were 1,642 medical schools worldwide in 157 countries'. Unfortunately, there are no international standards or guidelines to judge both subjectively and objectively, the quality and quantity of these medical schools in terms of the basic medical education or curriculum and subsequent postgraduate medical education and programmes. It is estimated that more than one third of FMG residents come from India, Pakistan and China and about $40 \%$ of them train in New York and California with almost half of them training in internal medicine or medical sub specialties ${ }^{2}$.

FMGs who wish to seek residency training in the US should note the following facts: ${ }^{3}$

Important differences exist in the medical school training of most FMGs and those of American medical students. In the past decade, an increased number of FMGs had been accepted into residency programmes in the US by

${ }^{*}$ Correspondence 
participating in the National Residency Matching Programme (NRMP). For instance, in the year 2001, $12.5 \%$ of those matched for the post-graduate year (PGY-1) were FMGs ${ }^{2}$.

FMGs now comprise $18-25 \%$ of residents-in-training in the US.

An Increasing number of FMGs are now remaining in the USA to practice upon completion of their residency training.

There is now some concern of possible oversupply of specialist physicians although problems of physician misdistribution and of inadequate access to a physician persist.

Since the events of September 11, 2001 when some foreigners hijacked four commercial airplanes and crashed them into landmark buildings, the US government and people have been reassessing current attitude towards foreigners in general and FMGs in particular.

This review provides helpful information to qualified medical students from the West African region who may be seeking residency training in USA.

\section{American healthcare system}

With an annual growth of 70 million people, the present world population of 6 billion will reach 7.5 billion by 2020 , and 9.3 billion by $2050^{4,5}$. This growth will be concentrated in South Asia and Africa. The current US population is approximately 290 million ${ }^{5}$ and healthcare is largely financed privately from either individual or employer-sponsored insurance. Forty million citizens have no healthcare insurance but are provided for through the government sponsored MEDICAID Program ". Also, over 40 million retired citizens, age 65 or older, are covered primarily by federal insurance MEDICARE. In particular, MEDICARE provides special Indirect Medical Education (IME) payments to teaching hospitals as reimbursement for their service and teaching mission. The total healthcare bill exceeds one trillion dollars, comprising 14\% of the national Gross Domestic Product (GDP). The federal, state, county, and municipal govcrnments pay over $45 \%$ of the bill ${ }^{6}$. Thus a sizeable portion of the resources for training doctors and other personnel are obtained ultimately from the American taxpayers.

\section{Medical education and residency training in the USA}

In the US, training to become a physician entails eight years of primary school, four years of high school, four years of pre-medical education at a college or university and four years of medical school. There are 125 allopathic medical schools accredited by the Liaison Commission on Medical Education (LCME) ${ }^{7}$. On obtaining the degree of doctor of medicine (MD) from any of the LCME-approved medical schools, the graduate sits for the USMLE and becomes eligible for medical licensure by the various states and, through the National Residency Matching Program (NRMP), for enrolment in graduate training programs approved by the Accreditation Council on Graduate Medical Education (ACGME) ${ }^{8}$.

There are more than 6,500 acute care hospitals in the US; 300 of these are major teaching hospitals but another 1,250 participate in graduate medical education (GME)" The American Hospital Association includes more than 5,000 hospitals, healthcare systems, networks or other providers of healthcare. Data from the American Medical Association Physicians' Master File showed that the number of graduates from US medical school practicing in the United States has increased by only $25.8 \%$ from 398,430 in 1985 to 501,236 in 1999 . On the other hand, the number of foreign-born FMGs practicing physician in the United States has steadily increased from 96, 16 in 1985 to 138,642 in 1999, an increase of $44 \%$ (Table 1) ". At present,

Table 1 Graduates of US \& Foreign Medical Schools practicing Physicians in the United states ${ }^{10}$. *

\begin{tabular}{lrllll}
\hline & 1985 & 1989 & 1994 & 1999 \\
All Graduates & 511,090 & 559,988 & 632,121 & 683,201 \\
Graduates from & & & & \\
$\begin{array}{l}\text { US Med Schools } \\
\text { Graduates from Foreign }\end{array}$ & 398,430 & 437,165 & 483,039 & 511,236 \\
Medical Schools & 112,660 & 122,823 & 149,082 & 158,710 \\
A. U.S.- Born & 16,344 & 18,905 & 19,275 & 20,060 \\
B. Foreign- Born & 96,316 & 103,918 & $129,80)$ & 138,642 \\
\hline
\end{tabular}

*Data from American Medical Association Physicians' Master tile

FMG's constitute over $20 \%$ of candidates enterir $\mathrm{g}$ residency training programmes each year in USA (Tables 2 (4) 3 ) $^{11,12}$.

During residency training, all residents from $\mathrm{PGY}-1$ to 5 take the annual American Board of Surgery In-Service Examination (ABSITE) and their performance at such examir ation counts towards their advancement. On the completion of residency, the trainees sit for the appropriate board qualification and certification examinations. A diploma is awarded to the successful candidates by the particular American Board of Nedical Specialty (ABMS). This diploma, as well as a state medical license, is a usual requirement for being granted clinical privileges to admit and treat patients at most US hospitals and clinics.

After the initial certification, most American Specialty Boards now require re-certification at five to ten ye r intervals. In preparing for re-certification, it is necessary to uresent evidence of participation in Continuing Medical Educat on (CME). This is readily obtained by attending appropriate accredited

Table 2 Graduates of US \& Foreign Medical Sc hools entering US residency programmes from 1988-1994 ${ }^{\text {is }}$ *

\begin{tabular}{|c|c|c|c|}
\hline \multirow[b]{2}{*}{ Year } & \multirow{2}{*}{$\begin{array}{l}\text { Graduates of US } \\
\text { Medical Schools }\end{array}$} & \multicolumn{2}{|c|}{$\begin{array}{l}\text { Graduates of Fo cign } \\
\text { Medical Schools }\end{array}$} \\
\hline & & US Born & Forign Born \\
\hline 1988 & 17,232 & 1,401 & 2,201 \\
\hline 1989 & 17,292 & 1,449 & 2,875 \\
\hline 1990 & 17,435 & 1,531 & 3,581 \\
\hline 1991 & 16,932 & 1,296 & 3,79 \\
\hline 1992 & 16,771 & 1,276 & $4,87 ?$ \\
\hline 1993 & 17,869 & 1,166 & 5,51 \\
\hline 1994 & 16,869 & 810 & $5,89 \|$ \\
\hline
\end{tabular}

* Data from Association of American Medical Colleges 
Table 3 Residents in training in U.S. Allopathic Hospitals ${ }^{(1)}$ *

\begin{tabular}{lcll}
\hline Academic & $\begin{array}{l}\text { Total } \\
\text { Year }\end{array}$ & $\begin{array}{l}\text { Graduates of Graduates of } \\
\text { Residents }\end{array}$ & $\begin{array}{l}\text { Schools } \\
\text { Foreign } \\
\text { Medical Schools }\end{array}$ \\
$1988-1989$ & 82,795 & 71,239 & 11,556 \\
$1989-1990$ & 87,001 & 73,680 & 13,321 \\
$1990-1991$ & 91,781 & 75,764 & 16,017 \\
$1991-1992$ & 95,162 & 77,020 & 18,142 \\
$1992-1993$ & 98,622 & 77,721 & 20,901 \\
$1993-1994$ & 102,341 & 78,581 & 23,760 \\
$1994-1995$ & 103,754 & 78,074 & 25,680 \\
$1995-1996$ & 104,612 & 77,849 & 26,763 \\
Increase from & & & \\
$1988-1989$ to & & & 15,207 \\
$1995-1996$ & 21,817 & 6,610 & $131.6 \%$ \\
\% Increase & $26.4 \%$ & $9.3 \%$ & \\
\hline
\end{tabular}

Data are from the Association of American Medical Colleges.

lectures, courses, workshops and meetings which are designed to keep the physician up to date on current concepts, knowledge, skills, and techniques. A variable number of CME credits are also required for the renewal of the medical license and for hospital re-credentialing.

More than 16,000 new physicians graduate annually from US medical schools ${ }^{10}$. There are approximately 24,000 entrylevel positions (PGY-1) for residency training at ACGME-approved hospitals ${ }^{3}$. The 8,000 unfilled positions are potentially available for the graduates of foreign medical schools. FMGs, whether US-born or foreign-born, comprise $18-25 \%$ of graduate training in the US in the past decade (Table 1$)^{10}$. Their numbers have increased at a faster rate than that of native-born graduates.

\section{The Educational Commission on Foreign Medical Gradu- ates (ECFMG)}

In a review of the year 1995/1996, WHO listed 1,642 medical schools in 157 countries '. Also the Foundation for Advancement of International Medical Education and Research (FAIMER ${ }^{\mathrm{sm}}$ ) <www.imed@ecfmg.org $>$ publishes an International Medical Education Directory (IMED) which provides current listings of medical schools recognized by the government agencies which are usually the ministries of health for each country. Although there are no international standards or accreditation guidelines for the basic curriculum or graduate education in these schools, their programmes may be assumed to provide appropriate training to meet the local and regional medical challenges. In order to assure uniform standards for credentialing FMGs applying for GME positions in the USA, the ECFMG was established in $1956^{10}$.

The ECFMG consists of representatives from the American Medical Association (AMA), the Association of American Medical Colleges (AAMC), the Federation of States Medical Boards (FSMB), the American Hospital Association (AHA), the American Board of Medical Specialties (ABMS), and the National Medical Association (NMA). The commission reviews the medical curriculum and screens the documents pertaining to the final medical diploma issued by the medical schools of the FMGs who seek graduate training in the US ${ }^{10}$. The current process of evaluation also includes the United States
Medical Licentiate Examinations (USMLE), Steps I and II; Test of English as a Foreign Language (TOEFL, <http:/ www.toefl.org $>$ ), which are held in various centres around the world; and the recently created Clinical Skills Assessment (CSA), which is administered at two centres; Philadelphia, Pennsylvanian and Atlanta, Georgia.

Eligibility for ECFMG certification includes a medical degree; successful completion of the USMLE I \& II, TOEFL and CSA; and a clear financial account with the ECFMG. Permanent validation of the ECFMG certificate (Form 246) is issued just before the beginning of residency training. Information regarding these examinations can be obtained from the ECFMG website, <http:/www.ecfmg.org> or <http:/ www.usmle.org>.

USMLE Step I assesses the candidate's ability to understand and apply important concepts of the sciences basic to the practice of medicine with special emphasis on the principles and mechanisms underlying diseaśe, and modes of therapy. There are 350 multiple-choice questions divided into seven 60 -minute modules of 8-hour duration ".

USMLE Step II assesses the candidate's ability to apply medical knowledge and clinical sciences to patients' care. The emphasis is on health promotion and preventive medicine; there are 400 multiple-choice questions in eight modules over nine hours.

The TOEFL tests the candidate's proficiency in English and the American idioms; it assesses listening, structure, reading and writing. There are 30-50 multiple choice questions based on listening to dialogues and short conversations which last 40-60 minutes. Another part of the test consists of 20-25 questions lasting 15-20 minutes which measure the recognition of language structure appropriate for standard written English. These are two types of questions: one comprises of incomplete sentences for which four words or phrases are provided and the candidate must choose the most appropriate of the four to complete the sentence. In the second type, sentences include underlined words or phrases; one of these must be changed in order to make the sentence correct. Reading skill is tested by providing a text which assesses the candidate's comprehension and vocabulary as 44-60 questions are answered in 70-90 minutes. Assessing the candidate's expression and elaboration of ideas on an assigned topic during 30 minutes tests the writing skill in English ${ }^{10}$.

Candidates for the CSA would have successfully completed the USMLE Steps I \& II and the TOEFL. Since 1998, this one-day test, which is administered only in Philadelphia and Atlanta, has been used to test the techniques of historytaking in English and of Physical examination. Ten standard patients are used for the test proper and an eleventh standard patient is used for research purposes. The candidates' skills at evaluation and management of these patients are assessed. Typical errors are made by lack of familiarity with the proper use of standard medical equipment such as the ophthalmoscope, tuning fork, otoscope, reflex hammer, and the sphygmomanometer for physical diagnosis. As of $1999,97 \%$ of the students taking the CSA examination had passed and failures were due to poor communication. In the 1999 residency matching programme, $64 \%$ of students who passed the CSA examination were matched with residency positions as opposed to $32 \%$ of ECFMG certificate holders without CSA certificate ${ }^{10}$.

Usually, the ECFMG provides sponsorship for the FMGs who have earned an ECFMG certificate and have also secured a contract offer for an ACGME-approved residency position for the duration of the training in the medical specialty 
of the candidate's own choosing. Training may last five to seven years, at the completion of which the FMG is expected to return to his or her home country. A two-year interval must then elapse before the FMG may re-enter the US for further training or practice ${ }^{12}$.

\section{The residency application process}

In the year 2000 and year 2001 , there were 96,806 residents in 7,985 approved residency programs in the USA $<$ http:I /www.acgme.org/ads $>; 24,707(25.5 \%)$ of these residents were FMGs ${ }^{13,14}$. Prospective applicants should make appropriate enquiries regarding these programmes by consulting the AMAGreen Book and the AMA-FREIDA on the Internet http:// www.ama.assn.org.freida. The candidate should then focus on two or three desirable specialties and states in a cost-effective manner on programmes that are most likely to accept FMGs (Tables 4 - 7) 2.3,10. 13,14.

The application, for the ACGME-approved residency position is now made by the Electronic Residency Application Service (ERAS) http://www.amsa.org/about/ programph/eras, which is organized by the National Residency Matching Programme (NRMP) <www.nrmp.org $>$. The electronic form must be filled completely, leaving no chronological gaps and accounting for all prior training and work experience. The NRMP also requires two recent photographs, supporting recommendations from two medical school teachers who vouch for the candidate's character and academic performance, as well as a letter from the Dean or Provost of the medical school of graduation. These letters should be addressed to each programme director by name rather than "to whom it may concern." The candidate's personal statement is also very important. It should include information pertaining to general formative background, core values, special awards and commendations, research activities and publications, civic and extracurricular activities as well as career goals and a definite affirmation of the commitment to return to the home country on completion of training. ${ }^{15}$. The academic transcripts and supporting documents should be mailed directly by the Registrar of the medical school of graduation to ECFMG office in Philadelphia. The applicant may expedite the process by paying for the cost of express or courier mail.

\section{The residency interview}

The interview process is usually conducted from October to February. Most programme directors have very good idea of what they look for in a resident and are quite adept as to how to extract the information from candidates. The purpose of the interview is for candidates to sell themselves, respond to questions eloquently and seek for information in a courteous and diplomatic manner. Another reason for the interview is to provide sufficient interaction between both parties in order to determine whether they would be suitable match for each other. Preparation is always the key word and if you don't sell yourself, no one else will do it for you. In preparing for the interview, the candidate should have researched the curriculum, hospital affiliations, subspecialty relations and the accreditation status of each programme. As you answer the interviewers' questions, always remember to highlight your best qualities and strengths.

Remember that the application form, all letters of recommendation and personal statement as well as USMLE, TOEFL and CSA scores would have been reviewed before the interview. Some of the key personality traits interviewers look for are: enthusiasm, motivation, initiative, communication skill, personality, energy, determination, humility, confidence, emotional control, common sense, good interpersonal skill, adapt-
Table 4 States with the highest number of foreign-born FMGs in residency positions in 1994-1995 '1"

\begin{tabular}{|c|c|c|c|}
\hline States & $\begin{array}{l}\text { Total \# of } \\
\text { Residents }\end{array}$ & $\begin{array}{l}\text { Foreign Born } \\
\% \text { of all Res } \\
\text { in the State }\end{array}$ & $\begin{array}{l}\text { Re idents } \\
\% \text { bf FMG } \\
\text { in the States }\end{array}$ \\
\hline New York & 15,088 & $39.7 \%$ & $28.3 \%$ \\
\hline Illinois & 5,757 & $31.3 \%$ & $8.6 \%$ \\
\hline Pennsylvania & 7,049 & $20.8 \%$ & $6.9 \%$ \\
\hline New Jersey & 2,741 & $43.6 \%$ & $5.9 \%$ \\
\hline Michigan & 4,129 & $27.0 \%$ & $5.3 \%$ \\
\hline Texas & 6.394 & $16.3 \%$ & $4.9 \%$ \\
\hline Massachusetts & 5,916 & $19.6 \%$ & $4.8 \%$ \\
\hline Ohio & 4.971 & $20.1 \%$ & $4.7 \%$ \\
\hline California & 9,877 & $9.7 \%$ & $4.5 \%$ \\
\hline Connecticut & 1,835 & $30.2 \%$ & $2.1 \%$ \\
\hline
\end{tabular}

irom Graduate Medical liducation Census

ability and intelligence. Other professional traits they look for are: reliability, honesty, integrity, pride, dedication, analytical and listening skills, ability to get things done on time, good work ethics and clinical judgment, and computer comp tence ${ }^{10,16}$. Some items in candidates' applications create grea concern to programme directors, such as disciplinary action in medical school, history of alcoholism, recurrent failure in rec uired clerkship, extended time in completing medical education, learning disability, repetition of USMLE Step I examination and low score in USMLE. Other areas of concern are graduating in the lower third of the class, failure in preclinical course and mediocre preclinical grades but strong clinical evaluation Participation in extracurricular activities might enhance a cancidate's credentials ${ }^{10}$.

On the other hand, applicants are also looking for congenial programmes that would nurture and provide good educational training and professional competence for them. When invited for interviews, the FMG should obviously plan to attend as many interviews as possible despite the recer t restraints of international travel. By responding early, the can lidate may be able to schedule the interviews into time clusters or by geographic location and thus save some time, expense, at $d$ stamina. The candidate should arrive in each city on the eve of the interview and establish a convenient route to the hospital. Men should be dressed appropriately, wearing a tie and jacket but without any ornamental display. A dark dress of appropriate length is recommended for women. The candidate should express enthusiasm for the programme and should niver show signs of discontent that may evoke negative respons: from the interviewer. A pinch of smile and laughter will sweetes the interview and make the day.

The candidate should make eye contact with the interviewer and answer the questions with confidence, calmness, and control in such a way as to project a favorable itnage. The candidate may in turn ask questions pertaining to ziny future changes in the programme's curriculum, faculty and resident turnover, opportunities for administrative training, res arch, and performance of the alumni in the certifying board exaininations and the percentage of FMGs in the programme. Saf sty of the parking facilities, demographics and patients' population, and the quality of contact with the clinical faculty should also be topics of interest to the applicant. It is essential to talk to the current residents away from the faculty members and the programme director; and if possible to residents who have left 
Table 5 Residents positions filled by specialist in NRMP_in $2000 \& 2001^{(2,3)}$

\begin{tabular}{lcccc}
\hline & \multicolumn{2}{l}{ Year 2000} & \multicolumn{2}{c}{ Year 2001 } \\
& US & Foreign & US & Foreign \\
& & & & \\
Family Practice & $57 \%$ & $8.3 \%$ & $49 \%$ & $9.0 \%$ \\
Int. Medicine & $63 \%$ & $17 \%$ & $13 \%$ & $16.0 \%$ \\
Pediatrics & $75 \%$ & $8.80 \%$ & $12 \%$ & $8.1 \%$ \\
O \& G & $75 \%$ & $3.92 \%$ & $15 \%$ & $4.6 \%$ \\
Surgery & $63 \%$ & $7.28 \%$ & $10 \%$ & $8.2 \%$ \\
Orthopedic & $88 \%$ & $1.8 \%$ & $6.0 \%$ & $0.7 \%$ \\
Ancsthesiology & $50 \%$ & $20.6 \%$ & $15 \%$ & $12.4 \%$ \\
Emerg. Medicine & $82 \%$ & $1.1 \%$ & $17 \%$ & $0.9 \%$ \\
Pathology & $38 \%$ & $26.3 \%$ & $18 \%$ & $22.5 \%$ \\
Transitional & $82 \%$ & $6.2 \%$ & $6.5 \%$ & $3.6 \%$ \\
\hline
\end{tabular}

the programme for other programmes. Because many candidates are typically interviewed for each of the positions available, it is advantageous for the FMG to be remembered in a favourable way. It is very important to send a thank you note to each of the interviewers and to indicate a strong interest in their programme.

\section{The ranking process}

When all the interviews have been concluded, members of the interview panel create a rank order of the interviewees, while each candidate also creates a rank order for the various programmes. The candidate's ranking considerations should include subjective and objective considerations while being cautious and realistic. Data from the Graduate Medical Education Census show the number of Foreign-Born graduates of FMG in residency positions in various States of America (Table 4) ${ }^{16}$. It appears that New York, Illinois, Pennsylvania, New Jersey, Michigan, Texas, Massachusetts, Ohio, California and Connecticut have the greatest concentration of FMGs. Graduates of foreign medical schools may want to take this information into consideration when choosing the locations of the programmes they wish to apply to. It is therefore important for FMGs to realize that they can only go to the institution they match with, unless they are offered contacts of employment outside the matching process, which is considered illegal by ECFMG. The FMG should also have an idea of how he/she performed during the interview. The applicant may want to know whether the programme is affiliated with a Veterans Affairs Medical Center (VAMC), which may be a positive factor and if there are subspecialty programmes in the institution, such as vascular, orthopeadic, neurosurgery, Head \& Neck surgery and plastic surgery, which may affect their clinical experience. Generally, West African FMGs should be realistic about applying to the top US programmes such as The Johns Hopkins Hospital, Massachusetts General Hospital, Mayo Clinic, Yale University programme, Hospital of the University of Pennsylvania, unless they have excellent credentials. These programmes are highly competitive even among graduates of US medical schools.

Unfortunately, the job of the programme director is to weed through the many applications to extract a group of potential good candidates who are likely to do well without creating too much grief and problems for the clinical staff. Another problem confronting FMGs involves the concern which some residency programme directors have about changes in the Medicare laws. These laws severely restrict the programmes' and hospitals' reimbursement for training non-US medical school graduates ${ }^{17}$. The Council on Graduate Medical Education (CGME) is also reexamining its position of limiting the number of PGY-1 residency positions for FMG to $110 \%$ of graduates of US medical schools and Osteopathic schools. The Council is also considering a proposition that will ensure that $50 \%$ of all FMG physicians entering practice in the US must be in primary care practice ${ }^{10}$.

\section{The National Residency Matching Program (NRMP)}

The "match" of each candidate to the programme is executed at the NRMP in Washington D.C. The computer-based algorithm allows candidates to be matched with the programmes, which have given them the highest ranking. The match results are released at noon Eastern Standard Time on the same date in mid-March nationwide. Applicants who have not been matched are informed the day prior to the announcement and a list of unmatched positions is also released. This allows such applicants to contact the programme directors directly for the unfilled positions. The results of the NRMP for 2000 and 2001 showed that the percentage of US medical students entering residency programmes have remained constant at $94 \%$, while the percentage of FMGs entering residency programmes in the US had increased from $39 \%$ in 2000 to $45 \%$ in 2001 (Table 8 ) $^{2}$. Clearly this is a significant increase of FMGs admitted to residency training programmes in the US. It is also a reflection of the important role that FMGs play in the health care delivery system of the US. Results of the 2000 and 2001 residency matching exercise also showed that FMGs have better chances of matching with internal medicine, general family practice, paediatrics, psychiatry, primary care, pathology, neurology and preliminary residency programmes (Table 6) ${ }^{13}$. Unfortunately, there is still tough competition in orthopaedics, Obstetrics \& gyneacology, ENT, plastic surgery, ophthalmology, general surgery, vascular and cardiothoracic surgery (Table 7) ${ }^{14}$. This however does not mean that FMG are excluded from such residency programmes but applicants to these programmes must have excellent credentials and good references. Despite the events of September 11,2001, the number of FMGs certified by ECFMG had increased.

Table 6 The ten specialties the FMGs find most common in establishing clinical practice in the United States ${ }^{16}$

\begin{tabular}{lccc}
\hline $\begin{array}{l}\text { Most common } \\
\text { Specialties }\end{array}$ & $\begin{array}{c}\text { Number of } \\
\text { FMGs }\end{array}$ & $\begin{array}{c}\% \text { of all } \\
\text { physicians } \\
\text { in specialties }\end{array}$ & $\begin{array}{c}\% \text { of all } \\
\text { FMGs }\end{array}$ \\
Internal Medicine & 40,843 & $32 \%$ & $23.1 \%$ \\
General/Family Practice & 16,896 & $21 \%$ & $9.5 \%$ \\
Paediatrics & 16,087 & $29 \%$ & $9.1 \%$ \\
Psychiatry & 11,677 & $30 \%$ & $6.6 \%$ \\
Anaesthesiology & 9,853 & $29 \%$ & $5.6 \%$ \\
General Surgery & 8,324 & $20 \%$ & $4.7 \%$ \\
Pathology & 5,798 & $32 \%$ & $3.3 \%$ \\
Cardiovascular Diseases & 5,417 & $28 \%$ & $3.1 \%$ \\
Neurological Sciences & 3,297 & $28 \%$ & $1.9 \%$ \\
Gastroenterology & 2,287 & $24 \%$ & $1.3 \%$ \\
\hline
\end{tabular}

Adapted from: American Medical Association: Physician Characteristics \& Distributions in US; 1999; Chicago, Illinois. AMA, 1999. Table A-6 
Table 7 The ten specialties the FMGs find most difficult in establishing clinical practice in the United States ${ }^{16}$

\begin{tabular}{lccc}
\hline $\begin{array}{l}\text { Most difficult } \\
\text { Specialties }\end{array}$ & $\begin{array}{l}\text { Number of } \\
\text { FMGs of all }\end{array}$ & $\begin{array}{l}\text { \% of all } \\
\text { physicians } \\
\text { in specialties }\end{array}$ \\
FMGs \\
O \& G. & 7,168 & $18 \%$ & $4.1 \%$ \\
Dermatology & 637 & $7 \%$ & $2.2 \%$ \\
Radiology (All aspects) & 3,915 & $14 \%$ & $1.5 \%$ \\
Emergency Medicine & 2,267 & $11 \%$ & $1.3 \%$ \\
Urology & 1.786 & $18 \%$ & $1.0 \%$ \\
Ophthalmology & 1.465 & $8 \%$ & $0.8 \%$ \\
Otolaryngology (ENT) & 1,046 & $11 \%$ & $0.6 \%$ \\
Plastic Surgery & 832 & $14 \%$ & $0.5 \%$ \\
Neurological Surgery & 732 & $15 \%$ & $0.4 \%$ \\
Occupational Medicine & 412 & $14 \%$ & $0.2 \%$ \\
\hline
\end{tabular}

Adapted from: American Medical Association: Physician Characteristics \& Distributions in US; 1999; Chicago, Illinois. AMA, 1999, Table A-7

Requirements and procedure for application of J-1 Visa Once matched, a contract or an official letter of employment from the programme director or the Hospital Director will be issued to the successful candidate. This is essential to complete the visa application. The accepting programme usually provides further information and guidelines for the J-I visa.

The majority of ACGME residency programmes in the US require the $\mathrm{J}-1$ visa.

The ECFMG certification and acceptance by an ACGME approved residency programme are pre-requisites for sponsorship for Exchange Visitor (J-1 visa) status. The ECFMG is the sole sponsor of non-citizen FMG's or IMG's for the federal Exchange Visitor programme ${ }^{13}$. This programme is designed to promote international cooperation and understanding. The J-1 visa is a temporary, non-immigrant visa that requires return to the home country for a minimum of 2 years following completion of the residency, whether successful or not. FMGs are also required to obtain statements of need from the Ministries of Health of their home countries or the last legal country of residence. The letter should give assurance of the country's need for the specialty of training and to confirm that the applicant would be offered a job at the completion of the training. Upon the completion of the ECFMG Form and establishing the applicant's eligibility, ECFMG will issue Form IAP-66, which is the certificate of eligibility for $\mathrm{J}-1$ visa. The certificate of eligibility and the completed visa form are submitted to the US Embassy in the applicant's home country or home of last residence for the issuance of J-1 visa. Following the J-I visa approval, planning and arrangements for travel to the USA is initiated. Upon arrival in the United States and obtaining a work contract from the hospital, the programme director or the designee will complete and sign Form 246 and mail it to ECFMG, who will then issue the applicant with the "Validity Indefinitely" sticker on the applicant's ECFMG certificate.

\section{Residents' orientation programme}

Almost all residency programmes devote a week of orientation for all new residents prior to the official starting date. Hence it is best to arrive in the United States 2-4 weeks prior to the July starting date. This provides adequate opportunity for looking for living accommodation, obtaining Social Security num- ber, a driving license, opening a bank account, purchasing a motor vehicle, and settling down before the beginning of orientation. Many programmes are planned during the orientation week including obtaining BLS, ACLS, and ATLS certifications. Rotations and call schedules are usually given early to allow subsequent vacation planning during the academic year.

Recent changes in ECFMG regulations relating to FMGs It is important for FMGs to know and understand the recent changes and restrictions in $\mathrm{J}-1$ visa status ${ }^{14}$, Two years ago, the ECFMG revised the regulations relating to FMGs with respect to changing from preliminary status to cat gorical status, or changing from one specialty training to another. Because the ECFMG believes that residency training is a progressive educational process, an FMG holding a J-1 visa m ly not complete a preliminary $P G Y-1$ position and then begin $c$ categorical PGY-1 position in the same specialty the following vear. Therefore, the FMG who is definitely interested in a gen ral surgery residency, for example, should seek a categorical PGY-1 position in General surgery ab-initio. This would aligr the 5-year residency in surgery with the 5-year duration of the J-1 visa for surgery, all other conditions being equal.

On the contrary, if the FMG accepts a preliminary PGY1 position in surgery with the hope of matching via the NRMP into a categorical PGY-1 position the following year, the ECFMG would issue the Form IAP-66 for only one year and the FMG would be required to register an alternative specialt interest at this stage. The FMG would then have only two opt ons for the following year. The first option is to find a categorice, $\mathrm{PGY}-2$ in surgery. This may be quite difficult, but if the search is successful, the ECFMG would issue another Form IAP. 66 for the remaining four years of surgical training. Thus, an FMG who enters a preliminary PGY-1 position in General surgery accepts the possible risk of option 2, which would terminate any further training in General surgery under the auspices of the ECFMG should the candidate fails to obtain categorical PGY -2 position in General surgery, which is not available through the matching process.

At present, the full length of time required to complete training for board certification is limited to 5-7 years depending on the specialty, and each year of training is contirgent upon satisfactory completion of the requirement for promotion throughout the length of the programme. FMGs are still allowed, with approval of ECFMG, to enter into addi ional Fellowship training programme after the completion of the initial residency training. FMGs should understand that any charge or

Table 8 Results of National Residents Matching, Programme: $2000 \& 2001^{(2)}$

\begin{tabular}{lccccc}
\hline & \multicolumn{2}{c}{ Year 2000 } & \multicolumn{2}{c}{ Year } & 2001 \\
& $\#$ & $\%$ & $\#$ & $\%$ \\
& & & & \\
& 1,114 & $57 \%$ & $1,0</ 8$ & $52 \%$ \\
$\begin{array}{l}\text { US Senior Medical Students } \\
\text { US Foreign Medical }\end{array}$ & 13,485 & $94 \%$ & $13,5 / 2$ & $94 \%$ \\
$\begin{array}{l}\text { Graduates } \\
\text { Non-US Foreign }\end{array}$ & 2,418 & $39 \%$ & 2,254 & $45 \%$ \\
Medical Graduates & 18,391 & $73 \%$ & $18,35 / 4$ & $77 \%$ \\
All Applicants & & & &
\end{tabular}


extension of visa status is the duty and under the jurisdiction of the USA Department of State and not the ACGME approved residency programme director or the ECFMG. Complicated issues relating to visa applications, denials, delays, etc., require legal consultation. In the USA these are done through immigration lawyers. They work with the individual solely, or in conjunction with the particular residency programme. Each state in the US has its own licensing requirements. Following or during the programme credentialing process, the individual state requirements are coordinated between the applicant and the accepting residency programme. Specific state requirements for physician licensure are available at www.visalaw.com/ho2feb/ 8hfebl02.html.

\section{Residents' remuneration and benefits}

Although some programme directors offer a competitive benefit package to applicants, in general, residents' remuneration and benefits depend on the year of training, the geographical location and the local cost of living. In the mid-western states such as Ohio, the basic salary varies from $\$ 40,000.00$ for PGY-1 to $\$ 44,000.00$ for PGY -5. In addition, PGY-1 \& 2 get two to three weeks of paid vacation while PGY-3 to 5 get three to four weeks of paid vacation ? All residents are given one week of educational leave to attend a scientific conference with additional time if presenting a paper at a national conference. The hospital pays for moving expenses within the United States, malpractice insurance, health and dental insurance and option for life and longterm disability insurance. Some hospitals also offer residents low interest loans of up to $\$ 1,000.00$ payable over 12 months, which is deducted from their monthly salary. Female residents may take short-term maternity, family and sick leave. In the last decade, an increasing number of women had entered general surgery residency training programmes and this had led to better understanding of their needs and greater tolerance of maternity and family leaves by their male colleagues, attending staff and programme directors.

\section{The new residents working hours}

In response to changes in health care delivery and concerns that sleep deprivation may have detrimental effects on patient safety, education and resident safety and well-being, the ACGME in September 2001 appointed a Work Group to examine residents' duty hours and their learning environment. The Work Group was to make concrete recommendations to ACGME regarding the responsibilities of the residency programmes, sponsoring institutions and the accrediting body relating to safe patient care and appropriate learning experience for residents. The recommendations by the Work Group which were adopted by ACGME stipulated that as of July 1, 2003:

(a) Residents must not be scheduled for more than 80 hours of work per week, averaged over four-week period, with the caveat that individual programme may apply to their sponsoring institution's Graduate Medical Education Committee (GMEC) for an increase up to $10 \%$, if they can prove a sound educational rationale.

(b) Residents should be given one free day in 7 days free of patient's care responsibilities, averaged over a four-week period.

(c) Residents should not be on night call more than every third night, averaged over a four-week period.

(d) Residents are limited to a 24-hour of on-call duty, with the additional period of 6 hours for inpatient and outpa- tient continuity and transfer of care, educational debriefing and didactic activities; no new patients may be accepted after the 24-hour duty.

(e) Residents should be provided with a minimum of 10hour rest period between duty periods; and

(f) When residents take call from home and are called back into the hospital, the time spent in the hospital must be counted towards the weekly duty hour limit.

The ACGME requires the residency programmes and their sponsoring institutions to have policies and procedures to monitor and support the physical and emotional wellbeing of their residents. Non-compliant programmes stand the risk of loosing their accreditation for residency training. With these new working hours, it is expected that the quality of life for residents would improve.

\section{Residents' evaluation}

All residents are assigned to mentors throughout their training. Each resident is evaluated after each rotation with constructive feedback. There is also a biannual review and discussion of each resident by the Residency Review Committee (RRC). The committee discusses each resident's clinical performance, professional ethics, and interaction with colleagues and other hospital personnel. Residents are also given the opportunity to evaluate their attending staff at each affiliated institution, the quality of the clinical and educational standards of their rotations and of the programme in general. All constructive comments and recommendations are taken seriously and acted upon. Residents who need assistance are offered appropriate help. Some residents may be placed on probation as a result of poor academic performance or poor interpersonal behaviour.

\section{Problems specific to West African FMGs in USA}

Many West African FMGs coming to the United States for residency training are often confronted with several challenges as a result of different medical curriculum, technology divide, attitude and cultural differences in approach to authority, interpersonal relationship and behavioural problems. In a country with many accents, the American patients complain that they have trouble understanding FMG care providers. In a survey of over 100,000 veterans across the United States, which was conducted about four years ago by VAMC in Washington DC, $25 \%$ of the veterans who responded expressed difficulties in understanding FMG care providers. While FMGs from West Africa do not have problems with English language, patients quite often have difficulties understanding their accents and intonations.

Married couples in medical profession also experience difficulties from lack of family support, house help, financial strain, the stress and strain of American life style and problems with raising children in an environment of different culture and social interplay. In spite of these challenges, the West African FMGs continue to make the best of the opportunity available to them while holding important positions in the arena of medical profession in the US.

\section{Factors responsible for poor performance and failure}

The ultimate success for residency training in the USA is multi-factorial. A focused career-plan is followed by adequate preparation to complete the application process. The visa issue is extremely important. Yearly checking and validation is the responsibility of the FMG. Failure to complete the residency programme involves both subjective and objective ele- 
ments. The objective elements include the language barrier, failure in the annual in-service examinations, and poor performance ratings on clinical rotations. The personal subjective clements include a wrong choice of career, involuntary change to another specialty, unhappiness with the matched programme, dissatisfaction with clinical and educational experience, loss of interest (burn out), rigors of the specialty with long days and nights, domestic problems and illness or death in the family.

Failure to continue with residency programme is rare with West African FMGs but may be seen in older or single residents who are undergoing personal and professional stress due to lack of self confidence, poor academic performance, depression, cognitive dysfunction, and lack of surgical skills. All these may eventually lead to drug and alcohol abuse and psychiatric illness 19,20. Fortunately, the frequency of failure among West African FMGs is quite low.

\section{Medical students from West African States}

A number of medical students from West African States have received further medical training in the US. The total number is unknown. It is also unknown as to how many have remained in the US. Because of a scandal in the mid-1980s in which two Caribbean medical schools traded in counterfeit diplomas, the ECFMG reacted by banning international medical students from taking clinical clerkships in US hospitals. At present, the AAMC precludes US medical schools from "co-mingling" their students with students from non-US medical schools during clerkships. However, after the events of September 11,2001, prolongation of training with visa extensions will likely become more difficult and complicated. As of today, there are 16 medical schools in Nigeria, two in Ghana and one in Liberia www.imed@ecfmg.org. Clearly there is a need for an increase in both the number and quality of physicians in the West African sub-region.

The quality of medical school education in West Africa was until recently very good but lately, the frequent school closures, strikes, lack of modern facilities, and technology may be adversely affecting the students. These medical students are typically intelligent, focused, eager to learn, and highly disciplined. In keeping with the British tradition, the examination process throughout the educational system is highly structured, and competitive. There is also lack of actual hands-on experience and responsibility. Despite these handicaps, applicants for the ECFMG certification and sponsorship have done quite well. Preparation to pass and succeed for the USMLE Steps I \& II; TOEFL; and CSA examinations include basic and clinical experience, practice, individual and group study, as well as taking the formal Kaplan school courses/curriculum. $<$ http://www. Kaplan.com>

\section{Guidelines for West Africans FMGs in ACGME-Approved} residencies in the US

It is extremely important to develop focused plan and goals for study in the USA. Personal considerations include financial and family support, and present/future obligations at home. The major goal must include returning home. This can be difficult once exposed to US environment. The lifestyle and advanced medical system may lure FMGs from returning home. An increasing number of West African FMGs tend to stay in the USA at the completion of their training. In choosing a residency programme, FMGs must look for programmes with affinity for FMG's. They must also try to network with other foreign medical graduates in the USA. Most programmes with a high FMG population are in rural areas and the inner city areas. As indicated earlier, the most popular specialties that FMG's match with are internal medicine, family practice, primary care, pediatrics, preliminary (transitional), psychiatry, and emergency medicine. The most difficult specialties include opl thalmology, orthopedics, general surgery, obstetrics \& gynecology, plastic surgery, ENT, and cardiothoracic surgery. Althougl the process is daunting and the journey is bumpy, with deternination and persistence, the goals can be achieved.

\section{Conclusions}

Foreign medical graduates planning to train in the United States should be prepared to work hard in order to achieve their goals. The events of September 11, 2001 will likely pose major and perhaps onerous obstacles to foreign medical st $u d e n t s$ with respect to Visitors and training visas. Besides, gettir g into good residency training programmes require good scores in USMLE steps I \& II, CSA and good performance at interviows. Before choosing residency programmes, FMGs should r search the various programmes and states which have affinity for FMGs. It is most desirable that all the required examinations (USMLE, TOEFL) be completed and passed at home before leaving for the United States. They must make arrangements for all letters of recommendations from their teachers and medical school Deans/Provosts before leaving home. Such letters should be written personally to the Programme Directors and not "to whom it may concern". The letters must be free from grammatical and spelling errors. The internet is a good source of information and can be used to obtain relevant information about programmes. Networking with friends and classmate who have gone through similar experience will be of valuable idvantage. Finally, once admitted into a programme, the trainee Inust create a good impression for the sake of future applicants rom West Africa. The prescription for success is hard work, :ocial and cultural adjustments and excellent performance in the annual InService examinations.

\section{Acknowledgements}

The authors wish to express their sincere than ss and appreciation to Ms. Carolyn Burris, the Surgical Reside tt Coordinator, Department of Surgery, Wright State University School of Medicine for providing the Information Resource for Residency Training. We also wish to extend our gratitude to Dr. Pesos Adedayo Olurin for sharing his personal experience with us as a FMG, who had gone through the various obs acles and problems expressed in this communication.

\section{Appendix 1 \\ Useful Internet sites for detailed information}

American Association of Colleges of Osteopathic Medicine (AACOM) www.aacom.org

American Association of International Medical Craduates (AAIMG) www.aaimg.com

American Medical Student Association (AMSA) www.amsa.org

Association of American Medical Colleges (AAMC) www.aamc.org

Educational Commission for Foreign Medical Gaduates (ECFMG) www.ecfmg.org

International Federation of Medical Students' Assciciations 
(IFMSA) www.ifmsa.org

International Medical Graduates website http:// home.earthlink.et/ alexfeo/

Legal information regarding visas www.twmlaw.com/resources/ medical/medical 4 cont.htm

The Princeton Review Guide for Students and Graduates of International Medical Schools www.review.com/medical/

\section{Abbreviations}

1. FMG Foreign Medical Graduates

2. ECFMG Educational Commission for Foreign Medical Graduates

3. GME Graduate Medical Education

4. NRMP National Residents Matching Program

5. PGY Post-Graduate Year

6. AHA American Hospital Association

7. IME Indirect Medical Education

8. GDP Gross Domestic Product

9. LCME Liaison Commission on Medical Education

10. MD Doctor of Medicine (Medical Doctor)

11. ACGME Accreditation Council on Graduate Medical Education

12. ABSITE American Board of Surgery In-Service Examination

13. ABMS American Board of Medical Specialists

14. CME Continuing Medical Education

15. FAIMER Foundation for Advancement Medical Education and Research

16. IMED International Medical Education Directory

17. AMA American Medical Association

18. AAMC Association of American Medical Colleges

19. FSMB Federation of State Medical Boards

20. NMA National Medical Association

21. USMLE United States Medical Licensing Examination

22. TOEFL Test of English as a Foreign Language

23. CSA Clinical Skill Assessment

24. ERAS Electronic Resident Application System

25. VAMC Veterans Affairs Medical Center

26. CGME Council on Graduate Medical Education

27. GMEC Graduate Medical Education Committee

\section{References}

1. World directory of medical schools. World Health Organization-Seventh Edition. 2000 Geneva, Switzerland

2. Lostumbo EM, Beran RL. Results of the National Resident Matching Program for 2000. Acad. Med. 2001; 75: 673676.

3. Lostumbo EM, Beran RL. Results of the National Resident Matching Program for 2001. Acad. Med. 2001; 76: 665668 .

4. Atlas of the World, Ann Harbor, Michigan, Harper Collins.
1999: 6 .

5. International Brief: World Population at a Glance: 1998 and Beyond. U.S. Department of Commerce Economics and Statistics Administration Bureau of the Census 1B/98-4 Issued January 1999.

6. Iglehart JK. The American health care system- expenditures. N Eng. J of Med. 1999; 340: 70-76.

7. Barzansky B, Atzel SI. Educational program in US medical schools, 2000-2001. J Amer Med Assoc. 2001; 286: 10291055.

8. Epstein AM. US Teaching Hospitals in the Evolving Health Care System. JAMA 1995; 273: 1203-1208.

9. MacGowan WAL. Surgical manpower worldwide. American College of Surgeons Bulletin 1997; 72: 5-19.

10. Iserson KV: In Iserson's getting into a residency: A guide for medical students. $5^{\text {th }}$ Edition, Tucson, Arizona. Galen Press Limited, 2000.

11. Thadai RA, Swanson DB, Galbraith RM. A preliminary analysis of different approaches to preparing for the USMLE step I. Acad Med. 2000; 75: 540-542.

12. Bell LB: In: The International Medical Graduates' Guide to US Medicine - Negotiating the Maze. Galen Press Publishers Limited. Tucson, Arizona, 1995.

13. Brotherton SE, Simon FA, Etzel SI. Graduate medical education: appendix II. J Amer Med Assoc. 2000; 286:10911101.

14. Brotherton SE, Simon FA, Etzel SI. US Graduate Medical Education, 2000-2001. JAMA 2001; 286: 1056-1060.

15. Hallock JA. ECFMG and the Challenges Facing International Medical Graduates. Association of American Medical Colleges, 2002; 5: 2-3.

16. Wagoner NE, Suriano JR, Stoner JA. Factors used by program directors to select residents. J Amer Med Ed. 1986; 61: 10 21

17. Iglehart JK. Health Policy Report, The Quandary over graduates of Foreign Medical Schools in the United States. NEJM. 1996; 334: 1679-1684.

18. Jonas RA. New visa limits for Foreign Medical Graduates: Crisis in Subspecialty cares in USA. Asian Cardiovase \& Thorac Annals 2001; 9: 250-252.

19. Bates $J$, Andrew $R$. Untangling the roots of some international medical graduates' poor academic performance. Acad Med. 2001; 76: 43-46.

20. Lavey RE. Sources of stress for residents and recommendations for programmes to assist them. Acad Med. 2001; 76: 142-150. 